CLINICAL STUDY

\title{
Is unilateral adrenalectomy an alternative treatment for ACTH-independent macronodular adrenal hyperplasia?: long-term follow-up of four cases
}

Cristina Lamas, José J Alfaro, Tomás Lucas, Beatriz Lecumberri, Balbino Barceló and Javier Estrada

Department of Endocrinology, Clínica Puerta de Hierro, University Hospital, Madrid, Spain

(Correspondence should be addressed to Javier Estrada, Department of Endocrinology, Clínica Puerta de Hierro, C/San Martín de Porres, 4. 28035 Madrid, Spain)

\begin{abstract}
Objective: ACTH-independent macronodular adrenal hyperplasia is a rare cause of Cushing's syndrome. Bilateral adrenalectomy is considered the treatment of choice, but the patient is obliged to receive lifetime steroid replacement therapy and is susceptible to adrenal insufficiency crisis. New therapeutic alternatives are being proposed as new etiopathological features of the disease are known. Unilateral adrenalectomy of the largest gland can be a safe and effective alternative, but only short-term follow-up is reported in the literature. We present four consecutive patients with ACTH-independent macronodular hyperplasia and long-term remission of Cushing's syndrome after unilateral adrenalectomy.

Subjects: Four consecutive patients (two males and two females, mean age 50.3 years) with Cushing's syndrome due to ACTH-independent macronodular adrenal hyperplasia underwent unilateral adrenalectomy of the largest gland.

Results: The weight of the resected glands ranged from 26.8 to $210 \mathrm{~g}$. Two patients suffered transient post-surgical adrenal insufficiency and had steroid replacement therapy for 60 and 14 months respectively. After a mean follow-up of 78.8 months (range 30-137 months) all the patients persist without any evidence of Cushing's syndrome. Urinary free cortisol and serum cortisol, after the adrenal insufficiency stage, have always stayed within their normal ranges, but cortisol circadian rhythm and suppressibility after dexamethasone have never normalized. No further enlargement of the contralateral gland has been documented 62 to 126 months after surgery in three of the four patients. Conclusions: Unilateral adrenalectomy can be an effective and safe alternative treatment for ACTH-independent macronodular adrenal hyperplasia, and can achieve long-term remission of Cushing's syndrome.
\end{abstract}

European Journal of Endocrinology 146 237-240

\section{Introduction}

Adrenocorticotropin (ACTH)-independent macronodular adrenal hyperplasia (AIMAH) is a rare cause of ACTH-independent Cushing's syndrome. It involves both adrenal glands which are massively enlarged and can reach 10 to 100 times their normal weight. Its etiology is unknown. However, recent studies have widely demonstrated the expression of ectopic membrane receptors in the adrenal cortex, including those for gastric inhibitory polypeptide (GIP), catecholamines, vasopressin, serotonin and luteinizing hormone (LH), probably due to dedifferentiation of the adrenocortical cells or mutations in the promoter regions or transcription factors. The stimulation of these ectopic receptors is a possible mechanism of cell growth and proliferation $(1,2)$. The hyperplasia seems to originate in a polyclonal fashion, although some of the larger nodules appear to demonstrate monoclonality $(3,4)$.

Bilateral adrenalectomy is considered the treatment of choice $(5,6)$. Unilateral adrenalectomy of the largest gland can be a safe and effective alternative, but only short-term follow-up is reported in the literature (7, 8). We present four consecutive patients with AIMAH and long-term remission of Cushing's syndrome, with normal serum and urinary cortisol levels, after unilateral adrenalectomy.

\section{Subjects}

We present four patients with AIMAH followed in our department since 1984 . They represent $1.6 \%$ of our series of 252 patients with Cushing's syndrome who attended our department. All of them presented with 
mild or moderate Cushing's syndrome. The diagnosis of AIMAH was based on elevated urinary free cortisol, serum cortisol unresponsive to low- and high-dose dexamethasone suppression tests, undetectable or low serum ACTH unresponsive to corticotropin releasing hormone, and bilateral adrenal enlargement with unilateral or bilateral macronodules. Their clinical characteristics are summarized in Table 1. A detailed case report of patient 1 has been published previously (9).

Unilateral adrenalectomy of the largest gland was performed in all four patients. The decision was based on high surgical risk in the first two patients, planning a subsequent contralateral adrenalectomy in a delayed surgery. In the third and fourth patients the decision was based on long-term remission of Cushing's syndrome seen in the two previous patients after unilateral adrenalectomy. The weight of the resected glands ranged from 26.8 to $210 \mathrm{~g}$ (Table 2). Well-delimited hyperplastic nodules, which ranged in size from microscopic clusters of cells to $3 \mathrm{~cm}$ in diameter, without internodular atropy, were seen in histopathological studies. Two cell populations were combined: large cells with clear cytoplasm, vacuoles and a small and dense nucleus, and small cells with eosinophilic cytoplasm. These findings confirmed the diagnosis of AIMAH.

Clinical improvement was evident in all the patients who showed weight loss and a lower need for antihypertensive and antidiabetic drugs after surgery. Patients 1 and 3 suffered transient post-surgical adrenal insufficiency and had steroid replacement therapy for 60 and 14 months respectively. Patients 2 and 4 had normal serum and urinary cortisol after surgery.

After an average follow-up of 78.8 months (range 30-137 months) all the patients persist without any evidence of Cushing's syndrome. Serum and urinary cortisol, after the adrenal insufficiency stage, have always been normal, but cortisol circadian rhythm and suppressibility after dexamethasone have never normalized. Abdominal computed tomography scans were obtained in three patients 126, 68 and 62 months after surgery: none of them showed enlargement of the contralateral gland. Follow-up data are presented in Table 2.

\section{Methods}

Plasma ACTH was measured by radioimmunoassay before 1989 (Immuno Nuclear Corporation, Stillwear, MN, USA) and thereafter by immunoradiometric assay (Nichols Institute, San Juan Capistrano, CA, USA). Plasma cortisol was measured by radioimmunoassay until 1992 (ICN Biomedicals, Costa Mesa, CA, USA, and Immunotech International, Marseille, France) and thereafter by time-resolved fluorescence immunoassay (Delfa System, Pharmacia, Wallac Oy, Turku, Finland). Cortisol was measured in unextracted urine at low $\mathrm{pH}$ by radioimmunoassay (Diagnostic System Laboratories, Los Angeles, CA, USA and ICN Biomedicals).

\section{Discussion}

Bilateral adrenalectomy is considered the standard treatment for ACTH-independent macronodular adrenal hyperplasia $(5,6)$. It completely resolves Cushing's syndrome, but the patient is obliged to receive lifetime steroid replacement therapy and is susceptible to adrenal insufficiency crisis.

As new etiopathological features of the disease are known, new therapeutic alternatives, specifically

Table 1 Baseline clinical characteristics of four patients with AIMAH.

\begin{tabular}{|c|c|c|c|c|}
\hline & Patient 1 & Patient 2 & Patient 3 & Patient 4 \\
\hline Sex & Male & Female & Female & Male \\
\hline Age & 54 & 46 & 48 & 53 \\
\hline UFC (nmol/day) & 802.9 & 1004.3 & 358.7 & 364.2 \\
\hline ACTH (pmol/l) & Undetectable & 2.64 & 1.10 & 1.06 \\
\hline $\begin{array}{l}\text { Low-dose DXM } \\
\text { test (plasma } \\
\text { cortisol, nmol/l) }\end{array}$ & 620.8 & 813.9 & 626.3 & 419.4 \\
\hline $\begin{array}{l}\text { High-dose DXM } \\
\text { test (plasma } \\
\text { cortisol, nmol/l) }\end{array}$ & 786.3 & 604.2 & 336.6 & 424.9 \\
\hline $\begin{array}{l}\text { Abdominal CT } \\
\text { scan }\end{array}$ & $\begin{array}{l}\text { Bilateral adrenal } \\
\text { enlargement, } 4 \mathrm{~cm} \\
\text { nodule in the right } \\
\text { gland }\end{array}$ & $\begin{array}{l}\text { Bilateral adrenal enlargement, } \\
\text { with nodular shape, } 3.5 \mathrm{~cm} \\
\text { nodule in the right gland }\end{array}$ & $\begin{array}{l}\text { Bilateral adrenal enlargement with } \\
\text { multiple nodules, two large nodules } \\
\text { ( } 3 \mathrm{~cm} \text { diameter) in the right gland }\end{array}$ & $\begin{array}{l}\text { Bilateral adrenal } \\
\text { enlargement, with well } \\
\text { defined macronodules }\end{array}$ \\
\hline $\begin{array}{l}\text { I-131-cholesterol } \\
\text { scan }\end{array}$ & $\begin{array}{l}\text { Asymmetric bilateral } \\
\text { uptake }\end{array}$ & - & Unilateral (right) uptake & $\begin{array}{l}\text { Asymmetric bilateral } \\
\text { uptake }\end{array}$ \\
\hline Pituitary imaging & Normal CT & Normal MRI & - & - \\
\hline
\end{tabular}

UFC, urinary free cortisol (normal value $<331 \mathrm{nmol} /$ day); ACTH, normal range 2.2-13.2 pmol//; DXM, dexamethasone; CT, computed tomography; MRI, magnetic resonance imaging. 
Table 2 Follow-up data of four patients with AIMAH, after unilateral adrenalectomy. Hormonal determinations at the last follow-up visit are presented.

\begin{tabular}{lllll}
\hline & \multicolumn{1}{c}{ Patient 1 } & \multicolumn{1}{c}{ Patient 2 } & \multicolumn{1}{c}{ Patient 3 } & Patient 4 \\
\hline Surgical procedure & Right adrenalectomy & Right adrenalectomy & Right adrenalectomy & Left adrenalectomy \\
Adrenal weight $(\mathrm{g})$ & 26.8 & 29.4 & 60 & 210 \\
Adrenal size $(\mathrm{cm})$ & $5.5 \times 4.5 \times 3$ & $6.4 \times 3.9 \times 2.6$ & $8.2 \times 5.4 \times 2.4$ & $16 \times 8.5 \times 3$ \\
Serum cortisol (nmol/l) & & & & 361.4 \\
0800 & 344.9 & 322.8 & 466.3 & 248.3 \\
2300 & 485.6 & 375.2 & 286.9 & 104.8 \\
UFC (nmol/day) & 105.7 & 168.3 & 63.5 & 1.08 \\
ACTH (pmol/l) & 1.70 & 4.58 & 72 & 30 \\
Follow-up (months) & 137 & 76 & 72 & 34 \\
\hline
\end{tabular}

UFC, urinary free cortisol (normal value $<331 \mathrm{nmol} /$ day).

directed to the ectopic hormonal receptors, are being proposed (1). A therapeutic trial with propranolol was started in one patient with AIMAH, after stimulation of cortisol secretion was found in response to upright posture and to isoproterenol infusion, and the reversibility of this effect by propranolol administration was demonstrated, due to the presence of beta-adrenergic receptors on the patient adrenal cells membranes (7). Unilateral adrenalectomy and the administration of propranolol maintained cortisol secretion within the normal range for seventeen months.

A woman with human chorionic gonadotropin (hCG)/LH-dependent Cushing's syndrome, that was clinically manifested transiently during her pregnancies and became constant after the menopause, was treated with leuprolide acetate: after 24 months of follow-up serum and urinary cortisol remained normal. No surgery was performed (10). Octreotide treatment reduced cortisol secretion and hypercortisolism symptoms for several months in two different patients with GIPdependent Cushing's syndrome and AIMAH $(11,12)$. Partial response to OPC-21268, a V1a-receptor antagonist, has been described in a patient with AIMAH and cortisol secretion responsiveness to vasopressin or to the upright posture test (13). Despite these encouraging findings, adrenal surgery remains the treatment of choice.

We consider that unilateral adrenalectomy is an effective and safe alternative treatment for AIMAH. We know steroidogenesis is inefficient in patients with AIMAH, since they have huge adrenal glands, with combined weights usually higher than $100 \mathrm{~g}$, while their cortisol secretion is modest, so that they usually have mildly elevated urinary free cortisol and mild and long-standing symptoms. Morioka et al. found the cortisol content in adrenal tissue from patients with AIMAH, measured by high performance liquid chromatography (HPLC), was definitely lower than that in cortisol-producing adenomas and even in normal adrenal glands (14). The activities of cytochrome P450c17, $\mathrm{P} 450 \mathrm{c} 21$ and $\mathrm{P} 450 \mathrm{c} 11$ were evaluated in one case, and all of them were reduced in the macronodules (14). Another possible explanation was given by in situ hybridization studies, which demonstrated that steroidogenic enzymes are differentially localized to the small and large cells that can be found in AIMAH adrenal tissue $(15,16)$. This inefficient steroidogenesis would suggest that a significant but incomplete removal of adrenal tissue may be enough to limit cortisol secretion to the normal range. The contralateral gland may even be unable to maintain normal cortisol levels, despite showing macronodular hyperplasia, and post-surgical secondary adrenal insufficiency after unilateral adrenalectomy occurs in some patients (patients 1 and 3 ).

Limited experience has been published about unilateral adrenalectomy in patients with AIMAH. Good results have been reported in a patient with GIP-dependent AIMAH that was completely asymptomatic, on steroid replacement therapy, one year after removal of the largest adrenal gland (8), and in another patient treated with unilateral adrenalectomy and propranolol, after 6 and 18 months of follow-up (7). We have no knowledge of longer follow-up times after unilateral adrenalectomy in patients with AIMAH.

There is some concern about the possibility of progressive growth of the remaining gland, with a parallel increase in cortisol secretion. Our experience does not support this concept, since morphological studies did not show any significant enlargement in three patients 62 to 126 months after surgery, and daily urinary cortisol excretion stayed within the normal range in all the patients. No adrenal enlargement was found in a patient with AIMAH treated with leuprolide acetate, without any surgical procedure, after 12 and 24 months of follow-up (10), nor in the two above-mentioned patients treated with unilateral adrenalectomy $(7,8)$.

The persistence of abnormalities in the cortisol circadian rhythm or in the dexamethasone suppression tests, that point to the autonomous function of the non-resected gland, could be another matter of concern. This situation is similar to the subclinical Cushing's syndrome that can be found in some adrenal incidentalomas. It remains controversial whether subclinical hypercortisolism carries a higher risk of 
hypertension, obesity or osteopenia, but the few longterm studies undertaken did not find increased morbidity after conservative management (17).

A second surgery to remove the contralateral gland could be undertaken if Cushing's syndrome recurs during follow-up, but long-term follow-up of these four patients (mean: 78.8 months, range: 30-137 months) suggests this eventuality is not expected.

We conclude that unilateral adrenalectomy of the largest gland can be an effective and safe treatment for AIMAH.

\section{References}

1 Mircescu H, Jilwan J, N'Diaye N, Bourdeau I, Tremblay J, Hamet P et al. Are ectopic membrane hormone receptors frequently present in adrenal Cushing's syndrome? Journal of Clinical Endocrinology and Metabolism 200085 3531-3536.

2 Lacroix A, N'Diaye N, Tremblay J \& Hamet P. Ectopic and abnormal hormone receptors in adrenal Cushing's syndrome. Endocrine Reviews 200122 75-110.

3 Beuschlein F, Reincke M, Karl M, Travis WD, Jaursch C, Abdelhamid S et al. Clonal composition of human adrenocortical neoplasms. Cancer Research 199454 4927-4932.

4 Gicquel C, Leblond-Francillrad M, Bertagna X, Louvel A, Chapuis Y, Luton JP et al. Clonal analysis of human adrenocortical carcinomas and secreting adenomas. Clinical Endocrinology $1994 \mathbf{4 0}$ $465-477$.

5 Lieberman SA, Eccleshall TR \& Feldman D. ACTH-independent massive bilateral adrenal disease (AIMBAD): a subtype of Cushing's syndrome with major diagnostic and therapeutic implications. European Journal of Endocrinology 1994131 67-73.

6 Stratakis CA \& Kirschner LS. Clinical and genetic analysis of primary bilateral adrenal diseases (micro- and macronodular disease) leading to Cushing's syndrome. Hormone and Metabolic Research $199830456-463$.

7 Lacroix A, Tremblay J, Rousseau G, Bouvier M \& Hamet P. Brief report: propranolol therapy for ectopic (beta)-adrenergic receptors in adrenal Cushing's syndrome. New England Journal of Medicine 1997337 1429-1434.
8 N'Diaye N, Hamet P, Tremblay J, Boutin JM, Gaboury L \& Lacroix A. Asynchronous development of bilateral nodular adrenal hyperplasia in gastric inhibitory polypeptide-dependent Cushing's syndrome. Journal of Clinical Endocrinology and Metabolism 1999 $842616-2622$.

9 Boronat M, Lucas T, Barceló B, Alameda C, Hotait H \& Estrada J. Cushing's syndrome due to autonomous macronodular adrenal hyperplasia: long-term follow-up after unilateral adrenalectomy. Postgraduate Medical Journal 199672 614-616.

10 Lacroix A, Hamet P \& Boutin JM. Leuprolide acetate therapy in luteinizing hormone-dependent Cushing's syndrome. New England Journal of Medicine 1999341 1577-1581.

11 Reznik Y, Allali-Zerah V, Chayvialle JA, Leroyer R, Leymarie P, Travert $\mathrm{G}$ et al. Food-dependent Cushing's syndrome mediated by aberrant adrenal sensitivity to gastric inhibitory polypeptide. New England Journal of Medicine 1992327 981-986.

12 Croughs RJ, Zelissen PM, van Vroonhoven TJ, Hofland LJ, N'Diaye N, Lacroix A et al. GIP-dependent adrenal Cushing's syndrome with incomplete suppression of ACTH. Clinical Endocrinology $200052235-240$.

13 Daidoh H, Morita H, Hanafusa J, Mune T, Murase H, Sato M et al. In vivo and in vitro effects of AVP and V1a receptor antagonist on Cushing's syndrome due to ACTH-independent bilateral macronodular adrenocortical hyperplasia. Clinical Endocrinology 1998 48 403-409.

14 Morioka M, Ohashi Y, Komatsu F, Jin TX, Suyama B \& Tanaka H. ACTH-independent macronodular adrenocortical hyperplasia (AIMAH): report of two cases and the analysis of steroidogenic activity in adrenal nodules. Endocrine Journal 199744 65-72.

15 Sasano H, Suzuki T \& Nagura H. ACTH-independent macronodular adrenocortical hyperplasia: immunohistochemical and in situ hybridization studies of steroidogenic enzymes. Modern Pathology $19947215-219$.

16 Wada N, Kubo M, Kijima H, Ishizuka T, Saeki T, Koike T et al. Adrenocorticotropin-independent bilateral macronodular adrenocortical hyperplasia: immunohistochemical studies of steroidogenic enzymes and post-operative course in two men. European Journal of Endocrinology $1996 \mathbf{1 3 4} 583-587$.

17 Reincke M. Subclinical Cushing's syndrome. Endocrinology and Metabolism Clinics of North America 200029 43-56.

Received 28 June 2001

Accepted 23 October 2001 